\title{
The Structural Design and Relevant Calculations of 4000 Asphalt Recycler
}

\author{
Feng $\mathrm{GaO}^{\mathrm{a}}$, Na Wang ${ }^{\mathrm{b}}$ \\ School of Construction Machinery, Chang'an University, Xi'an, Shaanxi, China \\ Key Laboratory of Highway Construction Technology and Equipment of Ministry of Education, \\ Chang'an University, Xi'an, Shaanxi, China \\ a751133499@qq.com; ${ }^{b} 1173625516 @ q q . c o m$
}

KEYWORDS: highways, pavement recycling, asphalt mixtures, hot recycling plant, asphalt pump, circulating oil pump

\begin{abstract}
With the development of economy in China, highways construction and maintenance are also in the rapid development. Infantile highways are entering the large-scale maintenance phase, which would leave a great deal of wasted asphalt mixture. They not only occupy land, pollute environment and cause resource waste. Developing the recycling technology of asphalt mixture has significant economic and social benefits. A self-propelled asphalt mixture recycling plants is flexible and convenient, it can recycle the original pavement asphalt materials to $100 \%$, maximizing the use of resources to protect the environment. Not only the old asphalt mixtures can be recycled anywhere at any time, but also the maintenance is very convenient. This paper mainly focuses on the structure and the simple calculation of the bitumen pump and the circulation oil pump in the 4000 self-propelled asphalt mixture recycling plants.

In recent years, with the increase of asphalt pavement and traffic volume year by year. There is a huge number of old asphalt in our country. China is a country with a little high-quality asphalt, so that recycling of asphalt is an extremely important technology. For road construction machinery industry, the meaning of the development of the economic environment, to produce high quality recycled materials bituminous asphalt recyclers is quite significant. For road construction organization, it can be seen from the last few years, the focus in recent years has gradually shifted from road construction to road maintenance. Asphalt recyclers as a key road maintenance equipment is especially important ${ }^{[1]-[2]}$. Overseas data show that ${ }^{[3]-[4]}$, when the asphalt mixture is recycled in plant, cost savings of about 30\%; when the asphalt mixture is regenerated on site, cost savings of about $80 \%$. So for asphalt recycling can not only generate social and economic benefits, but also generate huge economic benefits.

Asphalt recycling technology as a "green" technology, which is the road scarifying, asphalt material recycling. After crushing, screening, old asphalt mixture and new asphalt are mixed together to meet the requirements of recycled asphalt mixture ${ }^{[5]}$. Some developed countries have considerable attention to this technology very early. To the present, the technology is quite skillful, reaching the level of standardization ${ }^{[6]}$. China now although has many studies on asphalt recycling technology, and the country also has many of asphalt recycling equipment manufacturers for the production of renewable equipment, but China is not completely mastered asphalt recycling technology. The practical construction and application prove that the quality of a lot of recycled asphalt materials does not meet the requirements ${ }^{[7]}$.
\end{abstract}

\subsubsection{Types and characteristics of asphalt recyclers}

The method of asphalt recycling can be divided into hot and cold recycling. According to the recycling method, cold recycling can be divided into cold in-place recycling and plant mixed cold recycling, hot recycling can be divided into hot in-place recycling and hot central plant recycling ${ }^{[8]}$. Although the requirements of cold in-place recycling is low, production cost is not high, but the quality of recycled pavement is not very good, it is rarely used in the highway. Plant mixed cold recycling production process is almost no need to use special equipment. Because the old aggregate is not heated, the old asphalt mixture can only be treated as aggregate. What's more, it is not 
effective. The construction of hot in-place recycling is simple and the efficiency is high, but the practice proves that there are many limitations, which is not suitable for the recycling of highway pavement. Hot central plant recycling technology is currently the most widely used recycling technology. The mixture, produced by this technology, can not only repair the asphalt road surface of the upper layer, middle layer and bottom layer. But this technology needs to transport the waste asphalt mixture, it will increase the transportation cost, affect the efficiency of the work. [9] - [10]. This paper will design a self-propelled asphalt mixture recycling plants. While working, the old asphalt mixtures are broken and then sent to the mixing drum by the feeding device. The old asphalt mixtures are heated by the burner. As the old asphalt mixtures are heated and broken in the mixing drum. And then those old asphalt mixtures and some new asphalt sprayed by the asphalt pump are processed at the right time to obtain excellent asphalt mixtures, it not only avoids the round-trip transportation of old asphalt mixture, but also improves the working efficiency at the same time .The vehicle is flexible and convenient, it can recycle the original pavement asphalt materials to $100 \%$, maximizing the use of resources to protect the environment. Not only the old asphalt mixtures can be recycled anywhere at any time, but also the maintenance is very convenient. Figure 1 shows the two-dimensional structure and three-dimensional structure of the drum.

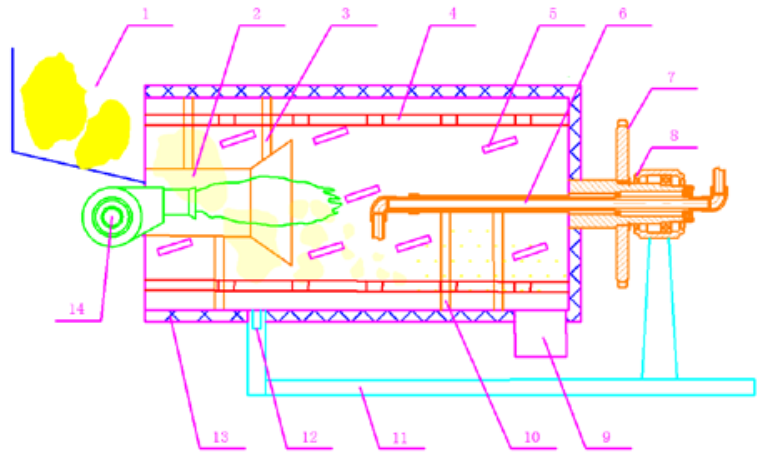

1-feed inlet;2- combustion sleeve;3- fan-shaped blade;4- lifting plate;5- spiral pusher blade;6- asphalt pipe;7-chain-drive mechanism;8-bearing block;9-outlet port;10-supporting baffle;11-chasis;12-support roller;13thermal insulator;14-combustion burner

(a) two-dimensional structure of the drum

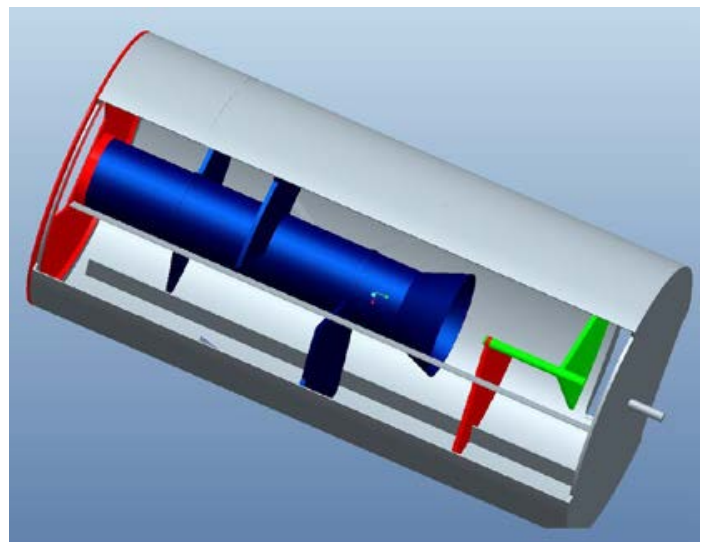

(b) three-dimensional structure of the drum

Figure 1 Model of asphalt recycling drum structure

The drum is divided into 4 zones: feed preheating zone, hot melt crushing ,mixing zone, discharge zone. The combustion sleeve is supported by 3 fan-shaped blade, with the interval of $5-10^{\circ}$, the thickness of $20 \mathrm{~mm}$. There is a combustion burner in the interior of the combustion sleeve, heat produced by combustion burner is transmitted to the fan blade and roller, and then transferred to the old asphalt mixture. Fan blades can heating and crushing of the old asphalt block, and extend the heating time in the drum. Spiral pusher blade and lifting plate is the important part of the drum. The main function of the spiral pusher blade is to push the old asphalt mixture imported by feeding mechanism forward. Of course, it can also play the role of broking asphalt. When the asphalt 
mixture is heated until it has softened, the force generated by the old asphalt contacting with the spiral pusher blade will result in old asphalt broken. The main role of lifting plate is to make the old asphalt and adding new asphalt mixing evenly, so that the mixture is brought up and down to form the curtain material. It can also play a role in breaking the old asphalt block.

As the roller rotating, the installation of the asphalt tank becomes difficult when the mixture is sprayed. Although the front end of the roller is fixed, the asphalt pipe can be fixed, but the block / heating plate is rotating with the drum, it will be blocked by the block/ heating plate. Therefore, asphalt pipe will be installed in the rear end of the drum, supported by a bearing seat so as to ensure that when drum rotating, asphalt pipe is not rotating. The installation of supporting baffle can not only support bitumen spraying pipe, but also can crush the old asphalt block and extend the mixing time of old asphalt mixture and new asphalt.

\section{Simple calculations of circulation pumps and bitumen pumps}

\subsection{Calculation of circulation oil pump}

During the hot asphalt recycling process, we need to add new asphalt to old asphalt mixture. In order to reduce the viscosity of bitumen, to ensure the flow of asphalt, asphalt tank must be heated. The traditional asphalt heating method is mainly directly heating the fire tube in the asphalt tank through the burner, then the heat of the fire tube heat the asphalt. This method has significant drawbacks, the most important one is that the fire-tube is heated unevenly. In this way, the temperature field outside of fire tube naturally is unevenly, which is easily lead to local high temperature, resulting in deterioration of asphalt aging. To the present, the common asphalt heating method is the use of heating oil circulation system for heating. This method has been widely accepted by the people in this way, and the asphalt is not easy to be aged.

\subsubsection{Match heating capacity}

When bitumen is heated, the heating capacity will directly affect the rate of temperature of asphalt. Suppose asphalt tank volume is 500L. The heating capacity can be calculated according to the following formula.

$$
Q=\frac{C_{\mathrm{a}} \mathrm{m}_{\mathrm{a}} \triangle \mathrm{t}}{\eta}(\mathrm{kJ} / \mathrm{h})
$$

Where: $\mathrm{C}_{\mathrm{a}}$----- the massic heat capacity of asphalt. It is generally replaced by the average value of the initial temperature and the end temperature of the massic heat capacity. The massic heat capacity of asphalt at different temperatures of the heat capacity can be interpolated from Table 5-1, $\mathrm{kJ} / \mathrm{kg}{ }^{\circ} \mathrm{C}$;

$m_{a}$---- the quality of asphalt in the asphalt tank at full load, kg;

$\Delta t$----design rate of temperature increase, ${ }^{\circ} \mathrm{C} / \mathrm{h}$;

$\eta$---- efficiency of the heating system.

Table 2-1 asphalt mass heat capacity at different temperatures

\begin{tabular}{|c|c|c|c|c|c|}
\hline Asphalt temperature $/{ }^{\circ} \mathrm{C}$ & $10 \sim 20$ & $20 \sim 60$ & $60 \sim 100$ & $100 \sim 150$ & $150 \sim 180$ \\
\hline Asphalt mass heat capacity $/ \mathrm{kJ} / \mathrm{kg} \cdot{ }^{\circ} \mathrm{C}$ & $1.10 \sim 1.25$ & $1.25 \sim 1.45$ & $1.45 \sim 1.65$ & $1.65 \sim 1.85$ & $1.85 \sim 2.20$ \\
\hline
\end{tabular}

Due to the heat loss of the whole heating system. The first part is the heat radiation through the exposed portion of conducting oil pipeline. The second part is the heat radiation through the heated asphalt tank. Here it comes to a question of efficiency, where a value of 0.7.

The heat required for $500 \mathrm{~L}$ asphalt from $20^{\circ} \mathrm{C}$ to $180^{\circ} \mathrm{C}$ :

$$
\begin{aligned}
& Q_{\text {吸 }}=\mathrm{cm} \Delta \mathrm{t} \\
& =1.35 \times 500 \times 40+1.55 \times 500 \times 40+1.75 \times 500 \times 50+2.0 \times 500 \times 30 \\
& =131750 \mathrm{~kJ}
\end{aligned}
$$

The thermal conductivity of the heat conducting oil is 0.432 . That means asphalt can only 
absorbs about $43.2 \%$ of heat of heat conducting oil. Therefore, the heat conducting oil need to provide the total quantity of heat is $\mathrm{Q}_{\text {总: }}$

$$
Q_{\text {总 }}=\frac{Q_{\text {吸 }}}{0.432}=304976.8 \mathrm{~kJ}
$$

The initial heating time is 4 hours, then the unit-time to spread heat to conducting oil is R.

$$
R=\frac{Q_{\text {总 }}}{\mathrm{t}}=\frac{304976.8}{4}=76244.2 \mathrm{~kJ} / \mathrm{h}
$$

The efficiency of stove for heating is about $70 \%$. We can get the value of Q as follows.

$$
Q=\frac{R}{\eta}=\frac{76244.2}{0.7}=108920 \mathrm{~kJ} / \mathrm{kg}
$$

The power $\mathrm{P}$ of the burner is obtained as follows.

$$
P=\frac{Q}{3600}=30.2 \mathrm{~kW}
$$

\subsubsection{Calculation of fuel consumption}

In the choice of fuel, we know that, the general situation is to use diesel as a fuel. Finding the relevant literature we can know that the combustion of diesel fuel is $4.28 \times 104 \mathrm{~kJ} / \mathrm{kg}$. Assuming that the fuel consumption is expressed in $\mathrm{V}$, we can get the value of $\mathrm{V}$ as follows.

$$
V=\frac{Q}{4.28 \times 10^{4} \times \eta \times \rho}
$$

Where: $Q$----Heating capacity, $\mathrm{kJ} / \mathrm{h}$. Its concrete results in the above calculations have been obtained;

$\eta$----Conducting oil furnace efficiency provided by the manufacturer, where it is tentatively scheduled for 0.84;

$\rho$----Density of diesel. The value of $0.84 \times 10^{3} \mathrm{~kg} / \mathrm{m}^{3}$.

Then we can get the following results.

$$
V=3.6 \times 10^{-3} \mathrm{~m}^{3} / \mathrm{h}
$$

According to unit conversion, we can get the diesel fuel consumption is $3 \mathrm{~kg} / \mathrm{h}$.

\subsubsection{Calculation of the circulation of heat conduction oil}

The circulation of heat conduction oil for heating system can be calculated as follows.

$$
q=\frac{Q}{\left(t_{2}-t_{1}\right) C \rho} \quad(5.3)
$$

Where: $Q$----The heating capacity of conduction oil furnace. The results is shown above;

$\mathrm{t}_{1}$----Temperature of inlet port of oil furnace, ${ }^{\circ} \mathrm{C}$;

$\mathrm{t}_{2}$---- Temperature of outlet port of oil furnace, ${ }^{\circ} \mathrm{C}$;

C----The average massic heat capacity of heat conduction oil. That is the arithmetic mean value of massic heat capacity of $\mathrm{t}_{1}$ and $\mathrm{t}_{2}$ times, $\mathrm{kJ} / \mathrm{kg} \cdot{ }^{\circ} \mathrm{C}$. The circulation of heat conduction oil is shown below.

$$
q=\frac{108920}{15 \times 2.6 \times 0.84 \times 10^{4}}=3.32 \mathrm{~m}^{3} / h=55.3 \mathrm{~L} / \mathrm{min}
$$

After finding the relevant heat conduction oil pump manufacturers, we finally choose the RY heat pump. RY heat pump is designed and manufactured in accordance with GB5662. It is a energy-saving new products. The high temperature oil pump, with excellent performance, reasonable and reliable structure, is suitable for conveying high temperature liquid without solid particles. The self radiating structure, changing the conventional water cooling structure, has the advantages of simple structure, small volume, saving the operating cost, good performance, operational reliability. This is the second generation of products on the basis of our country's 
digestion and absorption of foreign oil pump.. The basic structure is a single-stage, single suction, cantilever leg support structure. The inlet of the pump is axial suction, the center of the outlet is vertically upward. It is installed on the base with motor, so the installation is convenient. According to the above calculation, the heat pump type RY32-32-160, with the flow rate of $6 \mathrm{~m}^{3} / \mathrm{h}$., can meet the requirements.

\subsection{Calculation of flow rate of asphalt pump}

The calculation of asphalt pump needs to be calculated based on the relevant parameters.

In the calculation, the maximum output of the equipment is $4 \mathrm{t} / \mathrm{h}$, the discharge time is 6 minutes, the temperature of the recycled asphalt mixture is $130 \sim 180^{\circ} \mathrm{C}$. So we can know:

1) A discharging quality $m$ is shown as follows.

$$
m=\frac{4 \times 10^{3}}{10}=400 \mathrm{~kg} / \mathrm{h}
$$

2) The quality of new asphalt we need to add. By looking for "a high proportion of renewable production of hot mix asphalt mix design", we can know the content of asphalt in asphalt mixture is about $5 \%$. After deducting the old asphalt of the recycled mixture, the actual new asphalt content we need to add is about $2.21 \%$, which is the best. Therefore, the quality of asphalt $\mathrm{m} 1$ is shown as follows.

$$
m_{1}=400 \mathrm{~kg} \times 2.21 \% \times 5 \%=8.84 \mathrm{~kg}
$$

3) The volume $V_{1}$ of new asphalt we need to add is shown as follows.

$$
V_{1}=\frac{m_{1}}{\rho}=\frac{8.84 \times 10^{3}}{1}=8.84 \mathrm{~L}
$$

Note: The density of asphalt is between $0.97 \mathrm{~g} / \mathrm{cm}^{3} \sim 1.01 \mathrm{~g} / \mathrm{cm} 3$. When calculating, the density of the asphalt to be taken as $1.00 \mathrm{~g} / \mathrm{cm}^{3}$.

4) Suppose that once the asphalt was added within 20s, the calculation results of flow $q$ is as follows

$$
q=\frac{V_{1}}{\frac{20}{60}}=\frac{8.84 L}{\frac{20}{60}}=1.6 \mathrm{~m}^{3} / \mathrm{h}
$$

According to flow parameters, to find related asphalt pump products, we can choose LQB asphalt thermal insulation pump. The clamping sleeve and the pump body are cast into one body, the heat preservation effect is good. What's more, the various problems of the welding clamping sleeve can be avoided. The heat insulation pump has the advantages of simple structure, small pressure pulsation, stable flow, reliable operation, high speed, low noise, high efficiency, long service life, and self-absorption capacity. LQB asphalt insulation pump and motor directly connected with a flexible coupling, mounted on a cast iron plate (with AC, DC, explosion-proof motor base). It is easy for users to install and use. In view of many advantages, we choose the LQB in the selection of asphalt pump. The specific model of the asphalt insulation pump is LQB-2/0.36, with flow of 33.3L / min, import and export diameter of $25 \mathrm{~mm}$, matching motor of Y90L-4, power of $1.5 \mathrm{~kW}$, in accordance with the relevant requirements.

\section{Conclusion}

This article mainly talks about the structural design of 4000 asphalt recycler and relevant calculations about the circulation oil pump and asphalt pump. Based on the calculated parameters and related information, we select the relevant product type. This is a guide to the design and calculation of the asphalt recyclers.

\section{References}

[1]Shuan zhe Ren. Research on Hot Central Plant Recycling and its Key Technologies of Asphalt 
Pavement[D]. Xi'an: Chang'an University, 2008.

[2]Yan'e Gao. Study on the Design of Hot Mixture Plant Recycling [D]. Xi'an: Chang'an University, 2008.

[3]Morgan R D. Hot and cold recycling of asphalt pavements[R].U.S. Department of

Transportation Federal Highway Administration,1981:27-29.

[4] Epps J A. Guidelines for Recycling Asphalt Pavements[J]. Journal of the Association of Asphalt Paving Technologists,1980:12-13.

[5] Jian ming Yang, Shi jiao Yang, Shao feng Xiong, Jian He. The present situation and technology of the recycling of old asphalt pavement. Journal of University of South China,17, 2003 (01): $11-15$.

[6]Ning Wu. The Study of Central Plant Hot Recycling Mixture Reclaimed Process[D]. Xi'an: Chang'an University, 2009.

[7]Xian kang Zhang, Jia peng Liu. Research on recycling technology of asphalt pavement [J]. Yunnan highway science and technology, 1995, 3 (4): 15-18.

[8]Zhi long Yu. Study on pavement performance and construction technology of asphalt mixture with hot mix asphalt [D]. Chongqing: Chongqing Jiao tong University, 2013.

[9]Dong Wang. The Technical Application Research of Old Asphalt Hot-Mixed Recycling[D]. Chongqing: Chongqing Jiao tong University, 2013.

[10] Yan Zhang. Study on the Hot In-plant Recycling Design of Asphalt Mixture[D]. Dalian: Dalian University of Technology, 2013. 